\title{
Overruling and the instability of law
}

\section{Citation}

Gennaioli, Nicola, and Andrei Shleifer. 2007. "Overruling and the Instability of Law." Journal of Comparative Economics 35 (2) (June): 309-328. doi:10.1016/j.jce.2007.02.003.

\section{Published Version}

doi:10.1016/j.jce.2007.02.003

\section{Permanent link}

http://nrs.harvard.edu/urn-3:HUL.InstRepos:27867133

\section{Terms of Use}

This article was downloaded from Harvard University's DASH repository, and is made available under the terms and conditions applicable to Other Posted Material, as set forth at http:// nrs.harvard.edu/urn-3:HUL.InstRepos:dash.current.terms-of-use\#LAA

\section{Share Your Story}

The Harvard community has made this article openly available.

Please share how this access benefits you. Submit a story.

Accessibility 
NBER WORKING PAPER SERIES

OVERRULING AND THE INSTABILITY OF LAW

Nicola Gennaioli

Andrei Shleifer

Working Paper 12913

http://www.nber.org/papers/w12913

\author{
NATIONAL BUREAU OF ECONOMIC RESEARCH \\ 1050 Massachusetts Avenue \\ Cambridge, MA 02138 \\ February 2007
}

We are grateful to Olivier Blanchard, Filipe Campante, Edward Glaeser, Claudia Goldin, Oliver Hart, Elhanan Helpman, Anup Malani, Fausto Panunzi, Torsten Persson, Richard Posner, Ilia Rainer, Alan Schwartz, Kathryn Spier, Pablo Spiller, Mathew Stephenson, David Stromberg, and especially Louis Kaplow for helpful comments. The views expressed herein are those of the author(s) and do not necessarily reflect the views of the National Bureau of Economic Research.

(C) 2007 by Nicola Gennaioli and Andrei Shleifer. All rights reserved. Short sections of text, not to exceed two paragraphs, may be quoted without explicit permission provided that full credit, including (c) notice, is given to the source. 
Overruling and the Instability of Law

Nicola Gennaioli and Andrei Shleifer

NBER Working Paper No. 12913

February 2007

JEL No. K13,K4

\author{
Nicola Gennaioli \\ Stockholm University \\ Institute for International Economic Studies \\ SE-106 91 Stockholm, Sweden \\ Nicola.Gennaioli@iies.su.se \\ Andrei Shleifer \\ Department of Economics \\ Harvard University \\ Littauer Center M-9 \\ Cambridge, MA 02138 \\ and NBER \\ ashleifer@harvard.edu
}

ABSTRACT

We investigate the evolution of common law under overruling, a system of precedent change in which appellate courts replace existing legal rules with new ones. We use a legal realist model, in which judges change the law to reflect their own preferences or attitudes, but changing the law is costly to them. The model's predictions are consistent with the empirical evidence on the overruling behavior of the U.S. Supreme Court and appellate courts. We find that overruling leads to unstable legal rules that rarely converge to efficiency. The selection of disputes for litigation does not change this conclusion. Our findings provide a rationale for the value of precedent, as well as for the general preference of appellate courts for distinguishing rather than overruling as a law-making strategy. 


\section{Introduction}

In the common law tradition, the law evolves through the creation and revision of precedents by appellate courts (Stone, 1985). There are two principal forms of such revision in common law. The first, and more typical, is distinguishing, whereby an appellate court accepts the previous precedent, but limits the scope of its applicability and establishes a new rule for the circumstances in which the previous precedent no longer applies. The second, and less typical, form is overruling, whereby an appellate court simply replaces the precedent with a new rule. Overruling deserves some attention both because it is the form of precedent revision typically studied in law and economics (Rubin, 1977, Priest, 1977, Posner, 2003) and because it is sometimes used by the U.S. Supreme Court.

Political scientists find that, although there is some role of precedent in binding the U.S. Supreme Court's decisions, the Court overrules precedents incompatible with its political orientation (Brenner and Spaeth, 1995, Segal and Spaeth, 2002). Furthermore, Supreme Court judges vote based on their ideological preferences (George and Epstein, 1992, Brenner and Spaeth, 1995, Songer and Lindquist, 1996), follow only those prior Court decisions that are compatible with their own ideologies (MacKuen and McGuire, 2005), and do not revise their past votes after the Court they sit on has established a new legal rule they had voted against (Segal and Spaeth, 1996, 2002). Klein (2002) obtains similar results in a study of appellate and not just Supreme Court decisions.

This evidence indicates that judges’ policy preferences play a key role in shaping appellate courts' overruling behavior. What do these findings imply for the evolution of common law? Does overruling lead the law to converge in the long run? If so, does the law converge to efficiency? What is the role of the selection of disputes for litigation for the quality of law?

This paper presents a model of overruling by appellate courts. The model answers the above questions and allows us to compare the evolution of common law under overruling with that under 
distinguishing, not considered in this paper but investigated by Gennaioli and Shleifer (2007). One important question we do not address is the court's choice of overruling versus distinguishing when both options are open.

Like Gennaioli and Shleifer (2007), our model relies on two assumptions. First, consistent with the findings of political science, we assume that judges hold biases favoring different types of disputants, and that these biases vary across the population of judges. ${ }^{2}$ This assumption has its intellectual foundation in legal realism, the theory that sees judicial decisions as based largely on judges’ preferences and beliefs (Holmes, 1897, Radin, 1925, Frank, 1930, Stone, 1985, Posner, 2005).

Second, following Radin (1925) and Posner (2003, 2005), we assume that changing precedent is personally costly to judges: it requires extra investigation of facts, extra writing, extra work of persuading colleagues when judges sit in panels, extra risk of being criticized, and so on. "Judges are people and the economizing of mental effort is a characteristic of people, even if censorious persons call it by a less fine name” (Radin, 1925, p. 362). The assumption that, other things equal, judges would rather not change the law implies that only the judges who disagree with the current legal rule strongly enough actually change it. Posner (2003, p. 544) sees what he calls “judicial preference for leisure” as a source of stability in the law; we revisit this issue.

Using a model relying on these two assumptions, we examine the evolution of legal rules under overruling in the case of a simple tort: a dog bites a man (e.g., Landes and Posner, 1987). We ask when and how precedents evolve through overruling, what factors render such evolution more efficient, and whether legal rules converge to efficient ones. We also examine how the selection of disputes for litigation influences efficiency ${ }^{3}$.

\footnotetext{
${ }^{2}$ Legal scholars increasingly accept the importance of judicial ideologies for rulings on politically sensitive issues (e.g., Pinello 1999, Rowland and Carp 1996, Revesz 1997, Sunstein, Schkade, and Ellman 2004).

${ }^{3}$ The hypothesis that common law tends toward efficiency was introduced by Posner (2003, $1^{\text {st }}$ edition 1973$)$. Key studies include Rubin (1977), Priest (1977), Cooter, Kornhauser, and Lane (1979), and Cooter and Kornhauser (1979).
} 
In line with the evidence on Supreme Court and appellate decisions, we find that the probability of an appellate court's overruling a precedent increases in the distance between the precedent and the appellate court's own bias. This result implies that the conditions for judge-made law to converge to efficient legal rules are implausibly strict. When judges overrule precedents, not only does the law fail to be efficient, but it may not converge at all, as legal rules fluctuate between extremes. This outcome is especially likely when judicial preferences are polarized; in this case, judges are more likely to strongly disagree with the current precedent, and so more eager to change the law. Overruling only leads to efficiency when efficiency-oriented judges are more activist than the biased ones, provided judicial preferences are not too polarized. Legal volatility has important implications for the areas of law with significant judicial disagreement as measured, for example, by their political sensitivity. It is precisely in these areas of law, as opposed to the more apolitical ones, that overruling raises the volatility of legal rules and thus leads to efficiency losses.

This pessimistic assessment of common law evolution under overruling still holds when several moderating factors are at work, including the strategic behavior of forward looking judges. More interestingly, the selection of disputes for litigation does not necessarily encourage the evolution of legal rules toward efficiency. Indeed, when judicial biases are known to the potential litigants, a driving force behind litigation is the potential sympathy of the court. An efficient rule may well be appealed when a litigant has reason to believe that a sympathetic court will overturn it. This result stands in contrast to the mechanisms discussed by Rubin (1977) and Priest (1977).

This highly pessimistic assessment of the quality of legal evolution under overruling may explain why appellate courts in common law countries generally prefer distinguishing. As shown by Gennaioli and Shleifer (2007), while distinguishing does not guarantee convergence to efficient legal rules, it refines and improves the law on average because it responds to factual circumstances. Such a tendency is not present under overruling, which keeps the law as a blunt but changing instrument. 
Although we do not explicitly model the choice between overruling and distinguishing, our results suggest why an efficient legal system should rely on distinguishing as the main form of legal change.

The next section presents our model of precedent formation. Section 3 describes the efficient legal rules. Section 4 studies the evolution of law under overruling. Section 5 presents several extensions, including a model of selection of disputes for litigation. Section 6 concludes the paper. The proofs of Propositions are contained in Section 7.

\section{A Model of Overruling}

There are two parties, the owner $O$ and the victim $V$, as well as a dog. The $\operatorname{dog}$ bit victim $V$, who seeks to recover damages from $O$, the dog's owner. The dog was not on a leash, so to assess $O$ 's liability one should determine whether $O$ was negligent (and so is liable) or not (and so is not). The model is a one-dimensional version of the two dimensional model in Gennaioli and Shleifer (2007).

Let $P_{N P}$ be the probability that a dog bites victim $V$ if the dog's owner $O$ does not take precautions (he does not put the dog on a leash) and $P_{P}$ the probability that the dog bites $V$ if precautions are taken. Let $C$ be $O$ 's cost of precautions (e.g., the costs of putting the dog on a leash). First best efficiency requires that the dog owner takes precautions if and only if their cost $C$ is lower than the reduction in the probability of a bite (weighted by V's harm, which we normalize to 1). As indicated by the Hand formula, the first best is implemented by holding $O$ negligent and thus liable if $P_{N P}-P_{P} \geq C$, and not liable if $P_{N P}-P_{P}<C$. We assume that damages are high enough (e.g., punitive damages) that $O$ takes precautions whenever found liable. In this context, the question for the law is how to determine negligence from the facts of a case.

We assume that judges determine $O$ 's liability by using only one empirical dimension, the dog's

aggressiveness $a \in[0,1]$. A dog with $a=0$ is very peaceful (a golden retriever) and less likely to bite $V$ than a dog with $a=1$ (a pit bull). Although legal rules are based solely on $a$, in a specific dispute 
liability may depend on a variety of idiosyncratic and unverifiable factors in addition to aggressiveness. We call these latter factors $u$ and assume that both $a$ and $u$ are independently and uniformly distributed over the population of interactions between $O$ and $V$. We further assume that:

$$
P_{N P}-P_{P}=\left\{\begin{array}{ll}
\overline{\Delta P} & \text { for } a+u \geq 1 \\
\underline{\Delta P} & \text { for } a+u<1
\end{array},\right.
$$

where $\overline{\Delta P}>C>\underline{\Delta P}$. $O$ is optimally held liable if and only if the dog is sufficiently aggressive, i.e. if $a \geq a(u)=1-u$. We could allow for more general functions $\Delta P(a+u)$ linking $a+u$ to the benefit of the leash, but the assumption that $\Delta P(a+u)$ "jumps" at $a+u=1$ allows us to separate the probabilities of the different errors induced by a legal rule from their welfare cost.

A legal rule in this environment attaches a legal consequence ( $O$ liable, $O$ not liable) to every level of the dog's aggressiveness, $a$. How do appellate judges make legal rules? We assume that, when no legal rule deals with dog bites at the beginning, the appellate judge who reviews the case sets the rule by choosing a threshold on $a$, which we call $A_{1}$. Owners of dogs more aggressive than $A_{1}$ are held liable; owners of dogs less aggressive than $A_{1}$ are not. Once $A_{1}$ is set, if a later judge dealing with a dog bite overrules the initial precedent he discards $A_{1}$ and replace it with a new rule $A_{2}$. Stare decisis only binds in so far as it is costly for the judge to change the precedent. In particular, we assume that each judge changing the legal rule (after the first) incurs a personal effort cost $k$, regardless of what change he makes. We take $k$ to be a fixed cost, independent of the magnitude of precedent change. In Section 5, we allow more radical precedent changes to entail higher personal costs.

The model's timing is as follows. At $t=0$, the first judge establishes the aggressiveness threshold $A_{1}$. This precedent guides adjudication until another judge (if any) overrules at some $t^{\prime}$. The judge changing $A_{1}$ sets a new rule $A_{2}$, possibly giving rise to a new round of precedent change. 


\section{Optimal Legal Rules}

We now investigate the efficient - welfare maximizing - rules that provide the normative benchmark for our analysis of legal change and judge made law in Sections 4-5.

The owner of a dog with aggressiveness $a$ facing unverifiable factors $u$ decides whether to put the dog on a leash by considering the risk of liability under the prevailing legal rule. Under first best precautions (i.e., $O$ puts the dog on a leash whenever $a+u \geq 1$ ), social welfare is equal to:

$$
W^{F . B .}=-(1 / 2) \underline{\Delta P}-(1 / 2) C,
$$

where the probability of a bite when precautions are taken is normalized to 0 . In half the cases, precautions are not efficient and the parties bear the extra risk $\underline{\Delta P}$ of the dog biting the man; in the other half, precautions are efficient and $\operatorname{cost} C$ to society.

Legal rules in this model cannot attain the first best because they can only condition $O$ 's liability on $a$ and not on the unverifiable factors $u$. As a result, legal rules are necessarily imperfect, inducing either over-precautions by mistakenly holding $O$ liable, or under-precautions by mistakenly holding $O$ not liable, or both. What is the socially optimal legal rule in this context? Suppose that the law holds $O$ liable if and only if $a \geq A$. Then, $O$ is mistakenly liable if $a \geq A$ and $a<1-u$, which happens with probability $\operatorname{Pr}(L \mid N L)=\int_{A}^{1}(1-a) d a=(1 / 2)(1-A)^{2} . \quad$ In this case, $O$ takes overprecautions, whose (constant) marginal social cost is $\Lambda^{\text {over }}=C-\underline{\Delta P}$. In contrast, $O$ is mistakenly not liable if $a<A$ and $a \geq 1-u$, which occurs with probability $\operatorname{Pr}(N L \mid L)=\int_{0}^{A} a d a=(1 / 2) A^{2}$. In this case, $O$ takes under-precautions, whose (constant) marginal social cost is $\Lambda^{\text {under }}=\overline{\Delta P}-C$. Then, the loss of social welfare (relative to the first best) under $A$ is:

$$
\Lambda(A)=(1 / 2) \Lambda^{\text {under }}\left[A^{2}+\lambda(1-A)^{2}\right],
$$


where $\lambda=\Lambda^{\text {over }} / \Lambda^{\text {under }}$ is the relative social cost of over-precautions. With the threshold $A$, social losses are $\Lambda(A)$ - the average of over- and under-precaution costs under the error probabilities that $A$ introduces. The higher is $A$ (the more the initial rule favors $O$ ), the larger is the loss from underprecautions but the smaller is the loss from over-precautions. By minimizing (3) with respect to $A$, we find the optimal legal rule, which is the normative benchmark for our analysis.

Proposition 1: The optimal legal rule is given by $A_{L}=\lambda /(1+\lambda)$.

The optimal legal rule trades off the social cost of under- and over-precautions. The higher is the relative cost of over-precautions $\lambda$, the more lenient is the optimal rule (the higher is $A_{L}$ ). In particular, the optimal legal rule induces $\operatorname{Pr}(N L \mid L) / \operatorname{Pr}(L \mid N L)=\lambda^{2}$, namely the relative likelihood of under-precautions increases in the relative social cost of over-precautions.

With these results in mind, we can move on to study judicial lawmaking. We ask when and how judge made law evolves over time through overruling, and evaluate the efficiency of legal evolution. By efficiency we mean ex ante efficiency, before judge types are revealed.

\section{Overruling and Legal Evolution}

When a case comes before an appellate judge, he either retains the existing rule $A$, or overrules $A$ and sets a new threshold. ${ }^{4}$ Like social welfare, the utility of an appellate judge ruling on a dispute between $O$ and $V$ depends on the social costs induced by the rule. However, we assume that a judge's objective diverges from social welfare (i.e. expression (3)) because of his bias, which reflects his preference for $V$ or $O$ and induces him to rule in favor of his preferred party. Specifically, the utility of judge $j$ is given by:

\footnotetext{
${ }^{4}$ Judicial decision making in panels could moderate polarization of their views and lead to better law, but also lead to strategic behavior (Kornhauser 1992, Schwartz 1992). As shown by Revesz (1997) and Sunstein et al. (2004), panels sometimes lead to the convergence of member views to the bias of the majority, rather than to a moderate compromise.
} 


$$
U_{j}=-\beta_{V, j} \operatorname{Pr}(N L \mid L)-\beta_{O, j} \operatorname{Pr}(L \mid N L)
$$

Judges dislike making mistakes, but they do not dislike the two types of mistakes equally. $\beta_{O, j}$ and $\beta_{V, j}\left(\beta_{V, j}, \beta_{O, j} \geq 0\right)$ capture the preference of judge $j$ for $O$ and $V$, respectively: the larger is $\beta_{O, j}$, the more he is eager to hold $O$ not liable, the larger is $\beta_{V, j}$, the more he is willing to hold $O$ liable. In setting the threshold A, different judges trade off the social cost of under and over-precautions in different ways.

In our specification of judicial preferences, a judge's utility depends on the expected outcome arising from the application of a given rule, not from the resolution of a particular case. Such a judge would consider replacing a legal rule he dislikes even if the outcome of the specific case before him is the same under the new rule. A judge cares about having a rule in place that meets his idea of justice, rather than about delivering a desired outcome in a specific dispute before him. This assumption is particularly appropriate for appellate judges, who establish legal rules rather than resolve specific disputes $^{5}$.

There is a measure 1 of judges, who can be of three types: share $\gamma$ of judges are unbiased, with bias $\beta_{O, j} / \beta_{V, j}=\lambda$ reflecting social welfare; the rest are equally divided among pro- $O$ judges, with bias $\beta_{O, j} / \beta_{V, j}=\lambda \pi$ and pro- $V$ judges, with bias $\beta_{O, j} / \beta_{V, j}=\lambda / \pi$. Parameter $\pi(\pi \geq 1)$, measures the polarization of judges’ preferences: with a higher $\pi$, the preferences of pro- $O$ and pro- $V$ judges are more extreme (there is more disagreement among them). We assume that all judges have the same preference intensity and normalize it to $1\left(\beta_{V, j}+\beta_{O, j}=1, \forall j\right)$.

\footnotetext{
${ }^{5}$ For now, the judge is assumed to ignore the possibility that the rule he establishes will be changed in the future. We relax this assumption in Section 5.
} 


\subsection{The Decision to Overrule a Precedent}

The first judge adjudicating a dispute between $O$ and $V$ establishes the initial precedent. Suppose that the dispute comes up before judge $i$, with preferences $\beta_{V, i}$ and $\beta_{O, i}$. The judge then selects a threshold $A$ to maximize:

$$
U_{i}(A)=-(1 / 2) \beta_{V, i} A^{2}-(1 / 2) \beta_{O, i}(1-A)^{2}
$$

Define $\beta_{i}=\beta_{O, i} / \beta_{V, i}$ as the pro-O bias of this judge. Then judge $i$ sets:

$$
A_{1, i}=\frac{\beta_{i}}{1+\beta_{i}}
$$

The subscript indicates that $A_{1, i}$ is the initial precedent set by judge $i$. The result is intuitive: the more Pro-O is the judge, the more lenient he is (the higher is $A_{1}$ ). $A_{1}$ coincides with the efficient legal rule $A_{L}$ only if $\beta_{i}=\lambda=\Lambda^{\text {over }} / \Lambda^{\text {under }}$, i.e., if the judge is unbiased.

Under $A_{1, i}$, social losses are given by $\Lambda\left(A_{1, i}\right)$. Given the variety of judicial preferences, there is no reason to presume that $A_{1, i}$ is set efficiently, i.e. to minimize $\Lambda(A)$. If the case ends up before a pro-O judge $\left(\beta_{i}>\lambda\right)$, too many aggressive dogs roam and bite with impunity; if the case ends up before a pro- $V$ judge $\left(\beta_{i}<\lambda\right)$, too many peaceful dogs are put on a leash.

Does overruling of this initial precedent correct the inefficiency of the law? To answer this question, we must first ask when judges find it worthwhile to overrule $A_{1, i}$. To this end, suppose that precedent $A_{1, i}$ is in place, and judge $j$ takes the initiative to change the law. He then sets a new threshold $A_{2, j}$, equal to

$$
A_{2, j}=\frac{\beta_{j}}{1+\beta_{j}},
$$


where $\beta_{j}=\beta_{O, j} / \beta_{V, j}$ is the pro-O bias of judge $j$. To check if judge $j$ in fact overrules $A_{1, i}$, we must consider his personal incentive to do so. Judge $j$ overrules only if the benefit of doing so is larger than the effort and other costs of overruling. Using the judge's utility function, we find that judge $j$ overrules the precedent when:

$$
\left(A_{1, i}-A_{2, j}\right)^{2} \geq 2 k
$$

Since a judge overrules to set a rule reflecting his preferences, there is no need for him to repudiate a rule established by someone with the same views. Notice also that judicial behavior is symmetric: if judge $j$ overrules $A_{1, i}$, then judge $i$ overrules $A_{1, j}$. The smaller is the cost $k$, the higher the chance that a judge changes the law. When there are no costs of overruling, the judge always sets a new rule reflecting his own bias. But how do judges with a positive $k$ react to precedent? Since judges regain discretion through overruling, they are more activist when the prevailing legal rule is further away from their preferred one (see equation (8)). This is more likely to be the case if judges' preferences are more polarized ( $\pi$ is higher). In this way, the extent of disagreement among judges determines the long run configuration of law. The case of $\lambda=1$ illustrates this idea.

Proposition 2: If $\lambda=1$, there exist two polarization levels $\pi_{1}$ and $\pi_{2}\left(\pi_{1} \leq \pi_{2}\right)$ such that: i) If $\pi \leq \pi_{1}$ the initial precedent sticks forever; ii) If $\pi \in\left(\pi_{1}, \pi_{2}\right]$, precedent fluctuates between pro-O and pro-V legal rules unless the initial rule was unbiased; iii) If $\pi>\pi_{2}$, precedent fluctuates between pro$O$, pro-V and unbiased legal rules.

Polarization of judicial preferences determines whether judges overrule the initial precedent and thus the ultimate configuration of judge-made law. For low polarization, precedent remains at its initial configuration regardless of whether $A_{1}$ is set by a biased or an unbiased judge. At intermediate levels of polarization, pro- $O$ and pro- $V$ judges overrule each other. As a result, precedent oscillates between 
pro-O and pro- $V$ rules unless an unbiased judge sets the initial rule, which then becomes permanent. Unbiased judges stop being passive when $\pi \geq \pi_{2}$ as they begin to overrule extremists. At high levels of polarization, every judge pursues legal change. Overruling is highly problematic for convergence.

This proposition yields a key empirical prediction of our model, namely that, under overruling, legal rules are the more volatile, the higher is the dispersion of judicial preferences. In particular, looking across various areas of law, those areas with greater dispersion of judicial preferences (perhaps because they are more political) would see greater volatility of legal rules.

Little changes for $\lambda<1$. Since now pro-O judges disagree with unbiased ones more than the pro- $V$ ones do, there is a $\pi_{3}$ such that for $\pi \in\left[\pi_{2}, \pi_{3}\right)$ pro-O judges overrule unbiased judges even if pro- $V$ ones stay passive. Still, the main thrust of Proposition 2 is maintained: the volatility of the law increases in the polarization of judicial preferences.

\subsection{The Efficiency of Legal Evolution Under Overruling}

What about the ex ante efficiency of long run law? Does overruling of precedents lead to optimal legal rules? The benchmark here is $A_{L}$, the optimal one-dimensional rule we found in section 3. The following proposition explains when overruling leads to optimality:

Proposition 3: Under overruling, the law converges to efficiency if and only if all judges are unbiased. Moreover, social welfare falls as the level of judicial polarization rises.

In expectation, the law converges to the efficient rule $A_{L}$ only if there is full agreement among judges and their views are aligned with efficiency. When some judges are biased, there is a chance that the initial precedent is set by either a pro- $O$ or by a pro- $V$ judge. In either case, the law does not converge to an efficient rule. The contribution of efficiency-seeking judges to the efficiency of judge- 
made law is recognized by Posner (2003), but under overruling the conditions for full efficiency seem implausibly stringent.

Our model also implies that, under overruling, social welfare decreases in the polarization of judicial views. Not only does judicial polarization increase the volatility of the law but it also reduces its efficiency. Too see this clearly, note that when people take precautions based on the law of the moment ${ }^{6}$, expected losses are given by $E[\Lambda(A)]$, where the expectation is taken across all the legal rules that may obtain in the long run. Because $\Lambda(A)$ is quadratic in $A$, expected losses are proportional to:

$$
V(A)+E(A)\left[E(A)-2 A_{L}\right]+A_{L}
$$

The optimal legal rule should be unbiased, i.e., $E(A)=A_{L}$, and have zero variance $V(A)$. Unless all judges are unbiased, judge made law cannot achieve this outcome. Importantly, expression (9) shows that polarization mainly affects social welfare by raising the variance of equilibrium legal rules. As $\pi$ rises, $V(A)$ rises as well, and so do social losses under judge made law.

Proposition 3 underscores the cost of polarization, but it does not in itself prevent overruling from being beneficial in an evolutionary sense. The question then arises, is there a tendency for the law to improve over-time? The next result addresses this question.

\section{Corollary 1: Under overruling, expected social losses are (weakly) minimized for $k=+\infty$.}

Overruling of precedents does not improve the law on average. For a given level of polarization, welfare is independent of $k$. The reason is the model's symmetry: if an efficiency oriented judge overrules a biased precedent, then the biased judge overrules the efficient precedent, creating no overall tendency toward efficiency. Efficiency is the same for $k=0$ as for $k=+\infty$. Indeed, when $k=\infty$, there is no legal change, but uncertainty over the bias of the initial judge leads to social losses

\footnotetext{
${ }^{6}$ Precautions optimally follow this rule if in every period the same appellate court adjudicates all the disputes. In this case, the law can only change next period if the new appellate court has a different bias from the current one.
} 
of $E\left[\Lambda\left(A_{j}\right)\right]$ (where the average is taken across all judge types). The same social losses obtain under $k=0$, when the law fluctuates between pro- $V$, unbiased and pro-O rules. Despite such irrelevance, there might be some reasons why, under overruling, $k=+\infty$ is preferred. Such values as the predictability of the law or equal treatment may render a bad but stable law preferable to an equally efficient on average but unpredictable law.

The dismal performance of overruling is due to the symmetry of judges' behavior: by mutually overruling each other, active judges neutralize their respective impacts on the law. For legal change to be desirable, the odds of moving from a bad to a good rule should be greater than those of moving in reverse (Cooter and Kornhauser, 1979). When would that be the case? Efficient precedents are less likely to be overruled when unbiased judges are more activist than the extremists, i.e., have a lower overruling cost $k_{U}$ (Posner, 2003). This might be the case when judicial ability is positively correlated with both unbiasedness and peer respect, which reduces the private cost of legal change:

Proposition 4: If $k_{U}<k$, there exists $a \hat{\pi} \leq \pi_{2}$ such that, for $\pi \in\left[\hat{\pi}, \pi_{2}\right]$, the law converges to efficiency.

When the unbiased judges are more interventionist than the biased ones $\left(k_{U}<k\right)$, then not only is there a possibility for overruling to improve the law, but Posner's efficiency conjecture also holds. However, the activism of the unbiased judges is not sufficient for the law to converge to full efficiency and a further condition must be met: polarization should not be too extreme. Figure 1 below plots, for $k_{U}<k$, the set of $\pi$ for which overruling does or does not lead to full efficiency. 


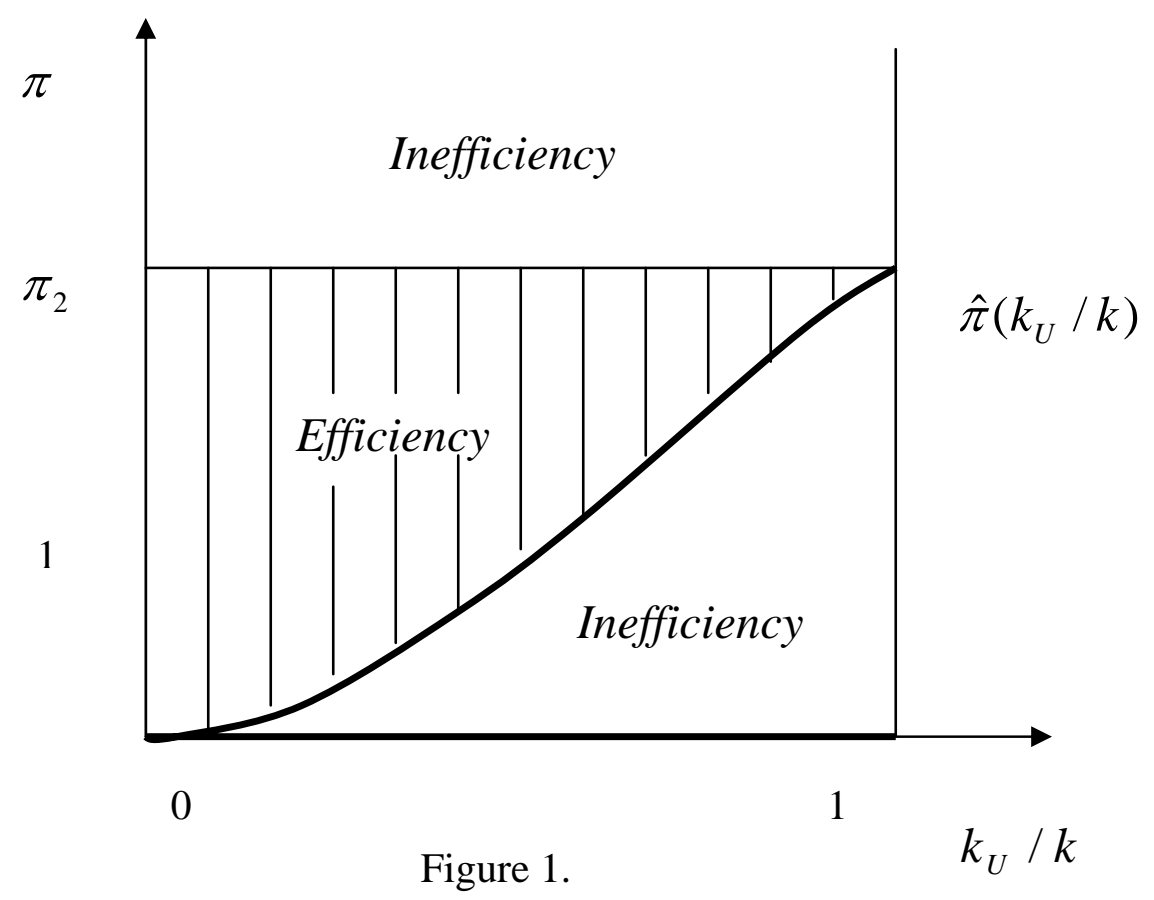

The vertical axis of the diagram measures preference polarization $\pi$, the horizontal axis measures $k_{U} / k \in[0,1]$, the strength of unbiased judges' comparative advantage in legal change, maximal at $k_{U}=0$ and minimal at $k_{U}=k$. The function $\hat{\pi}\left(k_{U} / k\right)$ shows, for every $k_{U}$, the level of polarization above which Unbiased judges overrule inefficient precedents. The dashed area and the bold lines delimit the set of parameters for which judge-made law converges to efficiency.

As in Proposition 3, Posner's conjecture holds - regardless of $k_{U}$ - when all judges are benevolent $(\pi=1)$. An intriguing feature of Figure 1 is that, in the shaded region above $\hat{\pi}\left(k_{U} / k\right)$, the law converges to full efficiency even if only a few judges are unbiased. Indeed, when $\pi \geq \hat{\pi}$, unbiased judges correct inefficient precedents, and when it is also the case that $\pi \leq \pi_{2}$, extremists stay passive and do not reverse the efficiency promoting decisions of the unbiased judges.

To summarize, our model suggests that if the behavior of different judges is symmetric, there is no tendency for overruling of precedents to be beneficial and - if judges' preferences are very 
polarized - convergence itself is unlikely. Moreover, the volatility of law increases with polarization of judicial opinions. These results are broadly consistent with the main finding of the political science literature, namely that the Supreme Court overrules precedents incompatible with its political orientation (e.g., Brenner and Spaeth, 1995, Segal and Spaeth, 2002). That literature indeed supports the key mechanism of our model, namely that the extreme judges are more likely to vote against the precedent than the centrist ones (Brenner and Stier, 1996) ${ }^{7}$.

At the same time, the results point to one force that leads to virtuous evolution of the law when judicial preferences are not too polarized, namely the greater activism of the Unbiased judges. Unfortunately, extreme polarization undermines this mechanism. Moreover, it is at least possible that the extreme rather than the unbiased judges face a lower personal cost of changing the law and hence are more activist, in which case we get even greater legal volatility than in the base model.

Our model suggests that especially in political areas of law where judicial preferences are very polarized, overruling of precedents is a source of volatility and unpredictability of legal rules. It does not create a tendency for the law to become more efficient.

\section{Factors Inducing Judicial Moderation}

The model studied so far abstracts from some factors that may foster judicial moderation, thereby reducing the extent of biased adjudication and the inefficiency of overruling. We now evaluate one at the time three leading factors that might induce judicial moderation: variable overruling cost, forward looking judges, and the selection of disputes for litigation. We show that the mere presence of these factors is not sufficient to guarantee the law's convergence to efficiency. In many circumstances, even when those moderating factors are at work, under overruling judicial bias is a source of volatility

\footnotetext{
${ }^{7}$ These skeptical conclusions about overruling contrast with the more benign assessment of distinguishing as a strategy of precedent change in Gennaioli and Shleifer (2007). In our models, distinguishing dominates overruling, and it seems unlikely that, in a model where both strategies are open to judges, overruling would improve the efficiency of legal change.
} 
of legal rules and efficiency losses. Section 5.4 then discusses some circumstances under which these factors are sufficiently strong to ensure convergence to efficiency.

\subsection{Variable Overruling Cost}

Suppose that a judge $j$ inheriting precedent $A_{t-1}$ and setting a new one $A_{t} \neq A_{t-1}$ at time $t$, must incur a variable overruling cost $C\left(A_{t}, A_{t-1}\right)=c\left(A_{t}-A_{t-1}\right)^{2} / 2$, with $c>0$, in addition to the fixed cost $k$. The variable overruling cost increases in the magnitude $\left|A_{t}-A_{t-1}\right|$ of the legal revision. This cost is a potential source for moderation because it discourages extremist judges to fully cater to their preferences. When a judge decides to replace $A_{t-1}$ by $A_{t}$, he solves:

$$
\max _{A_{t}}-\left(A_{t}-A_{j}^{*}\right)^{2}-c\left(A_{t}-A_{t-1}\right)^{2}
$$

Judge $j$ minimizes the sum of two costs. The first one is the loss he bears when $A_{t}$ differs from his preferred legal rule $A_{j}^{*}$. The second is the cost of setting $A_{t}$ far from $A_{t-1}$. Judge $j$ then sets:

$$
A_{t}=\frac{c}{1+c} A_{t-1}+\frac{1}{1+c} A_{j}^{*}
$$

Suppose that $k=0$. Then judges always engage in some overruling and equation (11) says that judge-made law follows an auto-regressive stochastic process converging to a distribution with mean $E\left(A_{j}^{*}\right)$ and variance $V\left(A_{j}^{*}\right) /(1+2 c)$. This suggests:

Proposition 5. If $k=0$ and $c>0$, the law converges to efficiency if and only if all judges are unbiased. A higher $V\left(A_{j}^{*}\right)$ increases the volatility of legal rules and reduces long run efficiency.

Even without a fixed cost of legal change, the variable overruling cost does not alter the message of Propositions 2 and 3. The variable overruling cost does not ensure legal convergence; it 
only reduces the magnitude of legal change and thus the volatility of legal rules from $V\left(A_{j}^{*}\right)$ to $V\left(A_{j}^{*}\right) /(1+2 c)$. However, the polarization of judicial views $V\left(A_{j}^{*}\right)$ still increases the volatility of the law and reduces its quality.

For a positive $k$, it is even less likely that efficiency is attained under a variable overruling cost. The variable cost reduces the benefit judges obtain from overruling. Although this effect may reduce the volatility of the law, it increases hysteresis, making more likely the scenario (associated with $k=+\infty$ ) in which the initial precedent sticks forever.

\subsection{Forward Looking Judges}

Another source of judicial moderation is forward looking judges: to reduce the possibility of future overruling, extremist judges may choose to set a less biased precedent today. We show that such strategic behavior may fail to induce convergence of judicial decisions to efficiency in a two period model where judges discount the future by a factor $\delta \leq 1$.

We solve the model by backward induction, starting from the final period two. If the initial precedent is $A_{i}$, then judge $j$ overrules it and replaces it with his desired legal rule $A_{j}^{*}$ when:

$$
\left(A_{i}-A_{j}^{*}\right)^{2}>2 k
$$

Judge $j$ leaves $A_{i}$ in place when $A_{i} \in\left[A_{j}^{*}-d, A_{j}^{*}+d\right], d \equiv(2 k)^{1 / 2}$. If desired legal rules $A_{i}^{*}$ are distributed on $[0,1]$ according to the c.d.f. $F(A)$, then in period one judge $i$ sets $A_{i}$ so as to:

$$
\min _{A_{i}}\left(A_{i}-A_{i}^{*}\right)^{2}+\delta\left\{\int_{\left[0, A_{i}-d\right] \cup\left[A_{i}+d, 1\right]}\left(A-A_{i}^{*}\right)^{2} d F(A)+\left(A_{i}-A_{i}^{*}\right)^{2} \int_{A_{i}-d}^{A_{i}+d} d F(A)\right\}
$$

Judge $i$ sets $A_{i}$ by trading off the cost of deviating from $A_{i}^{*}$ against the benefit of minimizing future overruling. The first term of expression (13) captures the judge's static gain from following his own 
bias. The term in curly brackets captures the strategic effect of $A_{i}$. The first integral is the judge's loss when $A_{i}$ is overruled, the second one is his loss when $A_{i}$ stays in place.

When $d=0$ or $d \geq 1$, judges set $A_{i}=A_{i}^{*}$. When $d=0, A_{i}$ is always overruled and has no strategic value. When $d \geq 1, A_{i}$ is never overruled, so it does not have strategic value either. Thus, when $k=0$ and $k \geq 1 / 2$, judge-made law is unaffected by forward looking behavior.

Roughly speaking, strategic effects call for maximizing $\int_{A_{i}-d}^{A_{i}+d} d F(A)$, the probability that $A_{i}$ stays in place. The cost of setting $A_{i}$ above $A_{i}^{*}$ is that more judges to its left (i.e. more pro- $V$ ones) overrule it, while the cost of setting $A_{i}$ below $A_{i}^{*}$ is that more judges to its right (i.e. more pro-O ones) overrule it. The strategic motive, then, does not necessarily lead judges toward efficiency. For instance, when $A_{i}^{*}$ is uniformly distributed in $[0,1]$, we have:

Proposition 6. For every $d \leq 1$, there exists an $\tilde{A} \in[0,1]$ such that, if $A_{i}^{*} \in[\tilde{A}, 1-\tilde{A}]$, then $A_{i}=A_{i}^{*}$; if $A_{i}^{*} \leq \tilde{A}$, then $A_{i} \in\left(A_{i}^{*}, \tilde{A}\right) ;$ if $A_{i}^{*}>1-\tilde{A}$, then $A_{i} \in\left(1-\tilde{A}, A_{i}^{*}\right)$.

When $A_{i}^{*}$ is uniformly distributed, a moderate judge is almost as likely to be overruled by a more pro- $V$ as by a more pro- $O$ judge. These two effects just cancel out for judges in the middle of the range (i.e., $A_{i}^{*} \in[\tilde{A}, 1-\tilde{A}]$ ), so that strategic motives do not affect their behavior. The two effects do not cancel out for extremists, who cater to more moderate judges to avoid being overruled too often. As a consequence, in the uniform case, strategic effects introduce some, but not full, moderation. Most important, moderation is unrelated to efficiency. When the efficient law lies outside of $[\tilde{A}, 1-\tilde{A}]$, the strategic motive also distorts the behavior of unbiased judges, making the law less efficient! Once 
again, when judges act strategically, greater polarization reduces welfare by increasing the volatility of the law, since the "non-strategic" range $[\tilde{A}, 1-\tilde{A}]$ widens.

In this model, judges' strategic motive can generate some tendency toward efficiency only if the proportion of unbiased judges is large enough that shading $A_{i}$ toward their tastes maximizes the probability of the rule's survival. To see this, let us go back to our example with three types of judges, where a fraction $\gamma$ of them is unbiased. Suppose for simplicity that the efficient legal rule is $A_{U}^{*}=1 / 2$ and that pro- $O$ and pro- $V$ judges are infinitely biased, so that $A_{V}^{*}=0$ and $A_{O}^{*}=0$. Moreover, suppose that $d<1 / 2$, so that the unbiased judges overrule a biased initial precedent. Then, we obtain:

Proposition 7. For every $d<1 / 2$, there exists a $\tilde{\gamma} \in[0,1]$ such that, for $\gamma \geq \tilde{\gamma}$ pro- $V$ judges set $A_{i}=1 / 2-d$, pro-O judges set $A_{i}=1 / 2+d$ and unbiased judges set $A_{i}=1 / 2$.

The strategic motive introduces a tendency toward efficiency only when there are enough unbiased judges, but the law is fully efficient only if all judges are unbiased. The extent of convergence depends on the overruling cost. When $k$ is large, convergence is weak or non-existent, as unbiased judges never overrule the biased ones. When $k$ is small, convergence may require the presence of many unbiased judges, as biased ones are unwilling to set the quasi-efficient precedents that are not overruled. Not only do strategic motives fail to eliminate the impact of bias on the law; they also reconfirm the role of unbiased judges in ensuring convergence to efficiency.

\subsection{Selection of Disputes for Litigation}

The selection of disputes for litigation may mitigate the costs of overruling. Rubin (1977) and Priest (1977) suggest that disputes involving inefficient legal rules are more likely to be taken to court rather than settled, leading to the replacement of such rules by better ones over time. This section 
shows that, when inefficient rules are a product of deliberate decisions by biased judges, this conclusion is unlikely to hold so long as the litigants do not put too much weight on the distant future. After having lost at trial, the party losing from the prevailing precedent would appeal even if the existing legal rule is efficient, especially if the current appellate court is biased in its favor. When the bias of the appellate court is incompatible with the precedent, efficient and inefficient rules are equally likely to be challenged. In this world, litigation and overruling of precedents reflect the evolution in the biases of appellate courts rather than the law’s convergence to efficiency.

To see this argument, consider the following model of litigation. After a dog bite has occurred, and in light of the existing precedent, the dog owner and the victim decide whether to settle or litigate. Litigation here corresponds to the litigants' decision to appeal the trial court's ruling. The cost of going to trial is sufficiently low that the parties’ decision to litigate in the first place is entirely driven by their later decision as to whether to appeal the trial court's ruling. The parties are assumed to know the preferences of the appeals court, which is especially realistic for litigation in front of the Supreme Court. Even if the court's bias is known, the parties may still fail to settle due to uncertainty about the court's overruling cost $k$. For example, the court's overruling cost is likely to depend on the quality of the parties' legal arguments. If the argument in favor of legal change is relatively weak then, even if the appellate judge disagrees with the existing precedent, he may prefer to leave it in place: it might be simply too costly to justify an overruling decision. The parties' uncertainty about their abilities to present to the appeals court a stronger argument may generate settlement failures and be a source of litigation.

For concreteness, assume that, by presenting their arguments in court, the parties render the appellate judge's overruling cost $k$ stochastic. With probability $p$ the party favoring legal change presents a stronger argument and $k$ becomes sufficiently low that the judge overrules the existing precedent. With probability $1-p$ the party against legal change presents a stronger argument and the 
judge keeps the existing precedent in place. Furthermore, the parties are allowed to have heterogeneous beliefs about $p$ : the party in favor of overruling believes that it will present a stronger argument with probability $p_{O} \geq p$, whereas the party in favor of the existing precedent believes that its argument will be weaker with probability $p_{P} \leq p . p_{O}-p_{P} \geq 0$ measures the divergence in litigants' beliefs: when $p_{O}-p_{P}$ is higher, there is more disagreement between the parties about their abilities to present a stronger argument. For simplicity, we assume that $p_{O}-p_{P}$ is unrelated to the extent of the judges’ disagreement with the current precedent.

Suppose that the prevailing precedent is pro- $V$ and is equal to $A_{V}^{*}$. In this situation, dog bites where $a<A_{V}^{*}$ or $a>A_{O}^{*}$ are not litigated because disputes involving extremely peaceful and extremely aggressive dogs are adjudicated efficiently by all judges. Things become interesting when $A_{V}^{*} \leq a \leq A_{O}^{*}$. Even in this range, if the current appeals court is pro- $V$, the case is not litigated because the dog owner is unable to obtain a more favorable ruling. However, if the current court is unbiased or pro- $O$, then the dog owner may appeal a trial court ruling against him, hoping to be released from liability through overruling. Indeed, if $A_{V}^{*} \leq a \leq A_{U}^{*}$ both unbiased and pro-O courts consider overruling $A_{V}^{*}$, while if $A_{U}^{*}<a \leq A_{O}^{*}$, only pro-V courts do.

As long as the current judge is willing to consider overruling, the expected utility of the dog owner from litigating is $-p_{O} D-X$ - where $D$ are the damages awarded in the lawsuit, $p_{O}$ is the probability that $O$ attaches to losing and $X$ is O’s litigation cost - whereas the victim's expected utility from litigating is $p_{P} D-X$. Litigation then occurs whenever:

$$
\left(p_{O}-p_{P}\right) D>2 X
$$

When condition (12) holds, the dog owner appeals the case and the current precedent is overruled in his favor with probability $p$. If the current appellate court is unbiased, the precedent 
becomes efficient with probability 1 because at least one among the multitude of dog owners involved in accidents eventually manages to win the dispute. By the same token, if the current appellate court is pro-O, then precedent becomes pro-O with probability 1 . For these reasons, the selection of disputes for litigation does not systematically render precedent more efficient. True, if the current court is unbiased, then the litigation incentives of dog owners are aligned with efficiency, but the same cannot be said if the current court is pro-O.

A fuller evaluation of the performance of judge made law under the selection of disputes for litigation calls for an evaluation of litigants' incentives under any existing precedent. The symmetry of our setup implies that the very same condition (12) predicts whether litigation occurs irrespective of whether the victim or the dog owner is bringing the appeal. We obtain:

Proposition 8. If $\left(p_{O}-p_{P}\right) D \leq 2 X$, the initial precedent sticks forever. If $\left(p_{O}-p_{P}\right) D>2 X$, the long run distribution of the law is described by Proposition 2 for $k=0$.

Selection of disputes for litigation does not necessarily promote efficiency in the long run. In our model, inefficient rules are appealed in front of both biased and unbiased judges, creating no tendency for the law to improve over time. Indeed, in the current example, selection of disputes for litigation yields the maximal long-run volatility in the law, namely the one prevailing in the basic model when the overruling cost is zero.

It is useful to compare our dismal result with those, more optimistic, findings of Priest (1977) and Rubin (1977). Priest (1977) argues that inefficient laws create larger stakes and are thus litigated more often than efficient ones, which improves the law over time. In our model, the stakes of the case are fixed and equal to $D$. However, if in our model appellate judges are allowed to also set new damages, the pro- $V$ judges would presumably set extremely high damages and pro-O judges extremely low ones. For any given rule, this would increase the stakes of litigating in front of a biased judge, 
effectively facilitating litigation when the current court is very biased. Strategic litigation in front of biased judges weakens the effect Priest (1977) had in mind.

Rubin (1977) argues that inefficient precedents are more likely to be litigated than the efficient ones if parties are concerned about the future. This effect is due to asymmetric stakes: the gain to the efficiency oriented party in moving from an inefficient to an efficient rule is greater than the loss to the inefficiency oriented party. In our model, this effect is unlikely to obtain. As Proposition 8 shows, conditional on litigation taking place, the law exhibits a lot of volatility. As a result, if - due to judicial bias - efficient precedents are not more likely to stick in the future than inefficient ones, the litigants' decision is unlikely to put a lot of weight in the future. This feedback from expected future litigation to present litigation paves the way for equilibria where high future inefficient litigation leads to a presentday bias in litigants' decisions, thereby inducing a lot of inefficient litigation today. This mechanism weakens the effect Rubin (1977) had in mind.

\subsection{Strong Forces Leading to Moderation and Efficiency}

The previous subsections showed that the mere presence of certain moderating factors such as forward looking judges and the selection of disputes for litigation does not guarantee the law's convergence to efficiency. These factors do not prevent overruling from being driven by the bias of the judge (in conjunction with the bias of litigants), in line with empirical evidence. These robustness checks confirm the model's basic message that overruling increases the volatility of the law without inducing a tendency toward efficiency.

Of course, the moderating factors may be sufficiently strong to ensure the law's convergence to efficiency or at least to avoid long run volatility in legal rules. This subsection discusses, without providing formal proofs, some assumptions needed to obtain long run stability. 
Begin with forward looking judges. In this case, even if the cost $k$ of changing the law is low, convergence to an efficient (or a fixed) legal rule may occur when judges are infinitely lived and repeatedly interact over their lifetimes. When judges are sufficiently patient, an efficient outcome can be sustained in equilibrium by a trigger strategy in which judges collectively respond to inefficient legal change by reverting to the myopic equilibrium, where the precedent is replaced with the current judge's preferred legal rule. In equilibrium, a biased judge is discouraged from overruling the initial efficient precedent: such a deviation would only pay off in the first period, when the biased judge's puts his preferred legal rule in place. However, such a deviation imposes two costs on the judge in the future. First, the judge loses insofar as the average legal rule $E(A)$ prevailing in the long run after a deviation is worse from the deviant judge's perspective than the efficient legal rule prevailing in equilibrium. Second, a risk averse deviant judge loses from the long run equilibrium variance $V(A)$ in legal rules prevailing after a deviation.

While these folk-theorem-type results are a theoretical possibility in models with infinitely lived and patient judges, in reality they are hard to obtain and do not square with the empirical evidence. The reason is that such results rely on very demanding assumptions concerning the ability of judges to: 1) coordinate on one specific equilibrium strategy among the many possible (and inefficient) ones, and 2) to condition their strategy on the entire history of the game.

A similar, but perhaps more realistic, accountability mechanism that might induce convergence toward efficiency hinges on judges' career concerns. Suppose, for example, that the legislature can intervene and punish judges who take deviant decisions (Spiller and Tiller, 1997). Then, as long as the legislature is efficiency oriented, such oversight induces judges to optimally leave an efficient precedent in place. Strictly speaking, such a model describes better the interaction between legal and legislative bodies than the autonomous evolution of a common law system of judicial law-making (unless the body overseeing judicial decision-making is itself a court, e.g., the Supreme Court). More 
important, this moderation mechanism is clearly vulnerable to the risk of biased oversight. When the legislature or the Supreme Court is itself subject to biases, its oversight would induce judges to adjudicate in a biased, not in an efficient, manner. The results would then be similar to our analysis of section 4, except that the bias of judicial decisions would reflect the bias of the overseeing body rather than the bias of the law-making court.

Finally, having forward looking litigants improves the selection of disputes for litigation. If litigants consider their future costs and benefits under different legal rules, then - as discussed by Priest (1977) - inefficient laws tend to generate a larger loss to the efficiency-oriented litigant than a benefit to the inefficiency-oriented litigant. Such asymmetric stakes imply that inefficient laws are more easily litigated and thus more likely to be replaced, improving the law’s efficiency over time. Unfortunately, although this effect can reduce the long run volatility of the law, it cannot ensure convergence to efficiency: given the incentive to litigate in front of a biased judge described in Section 5.3, efficient laws will always be litigated and replaced in the long run.

\section{Conclusion}

We have considered the evolution of common law under overruling of precedents by appellate courts, and compared the results to the case of distinguishing. As with distinguishing, we found that the conditions for ultimate efficiency of judge-made law are implausibly stringent. Strategic behavior by judges, costliness of radical legal change, and selection of disputes for litigation may mitigate but do not reverse these pessimistic conclusions. One case of convergence to full efficiency under overruling occurs when efficiency-oriented judges are more activist than the biased ones, and the preferences of the biased judges are not too polarized. In some areas of law, however, it is more plausible to expect that the most biased rather than the most efficiency oriented judges are the most activist. 
We also found that, for our case of overruling, disagreement among judges is likely to undermine the quality of legal change. This result implies that, in the areas of law with higher polarization of judicial views, we expect to see greater volatility of legal rules, as legal rules need not even converge, and lower efficiency. This finding contrasts with our results on distinguishing (Gennaioli and Shleifer, 2007), where some judicial disagreement, and thus some volatility in the law, is desirable as it allows legal evolution and improves the precision of the law.

These results point to some strategies for reducing the costs of judicial polarization under overruling. From an ex-ante perspective, the design and implementation of optimal appointment rules or training programs may help reduce the share of biased judges in the population and thus to improve the performance of judge-made law under overruling. From an ex-post perspective, suitably designed incentives such as short judicial tenure or optimal promotion/demotion policies might also help improve the performance of overruling. These policies, however, may also entail large costs of undermining the socially valuable judicial independence (La Porta et al., 2004).

At a broader level, our pessimistic assessment of the quality of law under overruling simply points to the value of precedents. The volatility of law under overruling is the flip side of the weakness of precedent, and the ease of changing it. With overruling, the evolution of law simply reflects the volatility of judicial bias. With distinguishing, because prior legal rules must be respected, the evolution of law instead reflects its refinement over time, even when judges are biased, and as a consequence has social benefits. This consideration implies that the preference for distinguishing relative to overruling by common law appellate courts, especially those in the UK, may be an efficient resolution of the tension between stability and change characteristic of any system of precedent. $^{8}$

\footnotetext{
${ }^{8}$ Although we do not model courts' choice between distinguishing and overruling, the distinguishing model of Gennaioli and Shleifer (2007) allows for some speculation. Just like overruling, distinguishing allows judges to rule according to their biases. However, relative to overruling, distinguishing also allows judges to benefit from the greater precision due to the introduction of new material dimensions into legal rules. We would then expect judges to prefer distinguishing to overruling as long as the informational benefit of the former is sufficiently large and overruling is not much cheaper.
} 
Unlike overruling, which encourages appellate courts to adjust the law to their own changing political or social whims, distinguishing encourages appellate courts to adjust the law to the changing factual circumstances, thereby fostering efficiency.

\section{Proofs}

Proof of Proposition 1. The optimal one-dimensional threshold rule $A_{L}$ is defined as

$$
A_{L}=\underset{A \in[0,1]}{\arg \min }(1 / 2) A^{2} \Lambda^{\text {under }}+(1 / 2)(1-A)^{2} \Lambda^{\text {over }}
$$

If $\Lambda^{\text {over }}, \Lambda^{\text {under }}>0$, the objective function is convex and $A_{L}=\left(\Lambda^{\text {over }} / \Lambda^{\text {under }}\right) /\left[1+\left(\Lambda^{\text {over }} / \Lambda^{\text {under }}\right)\right]$ is found by solving the f.o.c. $\left(A_{L} \Lambda^{\text {under }}-\left(1-A_{L}\right) \Lambda^{\text {over }}=0\right)$.

Proof of Proposition 2. Judge $j$ overrules $A_{i}$ when:

$$
f_{j, i} \equiv \frac{\left(\beta_{i}-\beta_{j}\right)^{2}}{\left(1+\beta_{i}\right)^{2}\left(1+\beta_{j}\right)^{2}} \geq 2 k
$$

Judges’ symmetric behavior considerably restricts the number of cases that we need to look at.

a) $\operatorname{Pro}-O\left(\beta_{i}=\pi \lambda\right) ; \operatorname{Pro}-V\left(\beta_{i}=\lambda / \pi\right)$. Now $f_{O, V}(\pi)=f_{V, O}(\pi)=\frac{\lambda^{2}\left(\pi^{2}-1\right)^{2}}{(1+\pi \lambda)^{2}(\pi+\lambda)^{2}}$.

b) Pro-O $\left(\beta_{i}=\pi \lambda\right)$; Unbiased $\left(\beta_{i}=\lambda\right)$. Now $f_{O, U}(\pi)=f_{U, O}(\pi)=\frac{\lambda^{2}(\pi-1)^{2}}{(1+\pi \lambda)^{2}(1+\lambda)^{2}}$.

c) $\operatorname{Pro}-V\left(\beta_{i}=\lambda / \pi\right)$; Unbiased $\left(\beta_{i}=\lambda\right)$. Now $f_{V, U}(\pi)=f_{U, V}(\pi)=\frac{\lambda^{2}(\pi-1)^{2}}{(\pi+\lambda)^{2}(1+\lambda)^{2}}$.

$f_{j, i}(\pi)$ increases in $\pi . f_{i, j}(1)=0, f_{O, V}(\infty)=1, f_{O, U}(\infty)=1 /(1+\lambda)^{2}, f_{V, U}(\infty)=\lambda^{2} /(1+\lambda)^{2}$. Call $\pi_{j, i} \in[1,+\infty) \cup\{+\infty\}$ the level of $\pi$ above which $j$ overrules $i$ (and vice-versa). Set $\pi_{i, j}=+\infty$ when $i$ and $j$ never overrule each other (e.g. $\pi_{U, O}=+\infty$ if $k>1 /(1+\lambda)^{2}$ ). Notice that for $\lambda \leq 1$, $\pi_{O, V} \leq \pi_{O, U} \leq \pi_{V, U}$. If $k>1 / 2$, precedent does not change; otherwise the law changes if $\pi$ is large enough. At $\lambda=1, \pi_{O, V}=\pi_{1} \pi_{O, U}=\pi_{V, U}=\pi_{2}$ and judge made law behaves as in Proposition 2 . 
Proof of Proposition 3 (and of Corollary 1). For every $k$, expected social losses are $E_{i}\left[\Lambda\left(A_{i}\right)\right] \equiv \alpha_{V} \Lambda\left(A_{V}\right)+\alpha_{B} \Lambda\left(A_{B}\right)+\alpha_{O} \Lambda\left(A_{O}\right)$, where $A_{V}, A_{B}, A_{O}$ are the preferred rules of Pro-V, Benevolent and Pro-O judges, respectively. At $k=0$, it is so because judges always overrule precedents. At $k \rightarrow+\infty$, the initial precedent sticks forever, but uncertainty over the first judge leads to the same expression. This is also the case for intermediate $k$ 's, because of the symmetry in judicial behavior: the effect of judge $j$ on law $A_{i}$ is exactly neutralized by the effect of judge $i$ on $A_{j}$. Thus, unless $\gamma=1$ the law does not converge to full efficiency. In line with expression (12), to study the impact of $\pi$ on social losses, consider its effect on $E\left(A_{j}\right)$ and on $V\left(A_{j}\right)$. After a little algebra, one finds that when $\lambda \leq 1, E\left(A_{j}\right) \leq A_{L}$ and $d E\left(A_{j}\right) / d \pi \leq 0$. Thus, a higher $\pi$ distorts $E\left(A_{j}\right)$ further away from efficiency. Moreover, it is also the case that $d V\left(A_{j}\right) / d \pi \geq 0$. Hence, polarization increases social losses.

Proof of Proposition 4. Efficiency is attained if Unbiased judges set $A_{L}$ without being overruled by extremists. This happens if $\pi<\pi_{O, U}$, which is necessary for $A_{L}$ to stay in place. The law can converge to $A_{L}$ either if Unbiased judges overrule all extremists, i.e. when $\pi \geq \bar{\pi}_{V, U}$ where $f_{V, U}\left(\bar{\pi}_{V, U}\right)=k_{U}$, or if Unbiased judges overrule only Pro-O ones, but at the same time Pro-O overrule Pro- $V$. This event happens when $\pi \geq \bar{\pi}_{O} \equiv \max \left[\pi_{O, V}, \bar{\pi}_{O, U}\right]\left(f_{U, O}\left(\bar{\pi}_{O, U}\right)=k_{U}\right)$. Call $\hat{\pi}=\min \left[\bar{\pi}_{O}, \bar{\pi}_{V, U}\right]$. Then, if $\pi \in\left[\hat{\pi}, \pi_{O, U}\right)$, the law converges to $A_{L}$. Clearly, it is always the case that $\hat{\pi} \leq \pi_{O, U}$. In order to draw figure 1 , suppose that $0<k<1 / 2(1+\lambda)^{2}, k$ fixed. Define now the variable $k_{U} / k \in[0,1]$. $\hat{\pi}\left(k_{U} / k\right)$ starts at $\hat{\pi}(0)=1$, ends at $\hat{\pi}(1)=\pi_{O, U}>1$ and it increases continuously in $k_{U} / k$.

Proof of Proposition 5. By inspection.

Proof of Proposition 6. Consider first the case where $d \in[0,1 / 2]$. Suppose $A^{1} \in[d, 1-d]$. Then, since $A_{j}^{*} \rightarrow U[0,1]$, the judge solves:

$$
\left.\min _{A^{1} \in[d, 1-d]}\left(A^{1}-A_{j}^{*}\right)^{2}+\delta\left\{\left(A_{j}^{*}\right)^{3}+\left(1-A_{j}^{*}\right)^{3}\right] / 3-2 d^{3} / 3\right\}
$$

thus, he sets $A^{1}=A_{j}^{*}$ iff $A_{j}^{*} \in[d, 1-d]$ Suppose instead that judge $j$ sets $A^{1} \leq d$. Then, he solves: 


$$
\min _{A^{1} \leq d}\left(A^{1}-A_{j}^{*}\right)^{2}+\delta\left\{\left(1-A_{j}^{*}\right)^{3} / 3-\left(A^{1}+d-A_{j}^{*}\right)^{3} / 3+\left(A^{1}-A_{j}^{*}\right)^{2}\left(A^{1}+d\right)\right\}
$$

The first derivative of the objective is $2 \delta y^{2}+2 y\left(\delta A_{j}^{*}+1\right)-\delta d^{2} \cdot y=A^{1}-A_{j}^{*}$ is the correction judge $j$ makes with respect to $A_{j}^{*}$. The candidates for the solution are $A^{1}=0$ or $A^{1}=A_{j}^{*}+\Delta_{+}$where $\Delta_{+} \equiv \min \left\{\left[\sqrt{\left(\delta A_{j}^{*}+1\right)^{2}+2 \delta^{2} d^{2}}-\left(\delta A_{j}^{*}+1\right)\right\rfloor / 2 \delta, d-A_{j}^{*}\right\}$. Thus, $A^{1} \in\left(A_{j}^{*}, d\right]$. Notice that $\Delta_{+}$decreases in $A_{j}^{*}$. $A^{1}=0$ is never optimal, as the judge prefers $A^{1}=A_{j}^{*}$ to it. Hence, if $A_{j}^{*} \leq d, A^{1}=A_{j}^{*}+\Delta_{+}$. Suppose that judge $j$ sets $A^{1} \geq 1-d$. Then, he solves:

$$
\min _{A^{1} \geq 1-d}\left(A^{1}-A_{j}^{*}\right)^{2}+\delta\left\{\left(A_{j}^{*}\right)^{3} / 3+\left(A^{1}-d-A_{j}^{*}\right)^{3} / 3+\left(A^{1}-A_{j}^{*}\right)^{2}\left(1-A^{1}+d\right)\right\}
$$

The first derivative of the objective is $-2 \delta y^{2}+2 y\left[1+\delta\left(1-A_{j}^{*}\right)\right]+\delta d^{2}$. Again, at the optimum $A^{1}=A_{j}^{*}+\Delta_{-}$, where $\Delta_{-} \equiv \max \left\{\left[1+\delta\left(1-A_{j}^{*}\right)-\sqrt{\left[1+\delta\left(1-A_{j}^{*}\right)\right]^{2}+2 \delta^{2} d^{2}}\right] / 2 \delta, 1-d-A_{j}^{*}\right\}$. Thus, $A^{1} \in\left(1-d, A_{j}^{*}\right)$. Notice that $\Delta_{-}$decreases in $A_{j}^{*}$. Hence, if $A_{j}^{*} \geq 1-d, A^{1}=A_{j}^{*}+\Delta_{-}$.

Consider now $d \in[1 / 2,1]$. If $A^{1} \in[1-d, d]$ the judge is never overruled. Thus, $A^{1}=A_{j}^{*}$ iff $A_{j}^{*} \in[1-d, d]$. If judge $j$ sets $A^{1} \leq 1-d$. Then, by using the same logic of before, one can define $\widetilde{\Delta}_{+} \equiv \min \left\{\left[\sqrt{\left(\delta A_{j}^{*}+1\right)^{2}+2 \delta^{2} d^{2}}-\left(\delta A_{j}^{*}+1\right)\right\rfloor / 2 \delta, 1-d-A_{j}^{*}\right\} . \Delta_{+}$decreases in $A_{j}^{*}$. Hence, if $A_{j}^{*} \leq d$, $A^{1}=A_{j}^{*}+\tilde{\Delta}_{+}$, so that $A^{1} \in\left(A_{j}^{*}, 1-d\right]$. Suppose that judge $j$ sets $A^{1} \geq d$. Then, one can define $\widetilde{\Delta}_{-} \equiv \max \left\{\left[1+\delta\left(1-A_{j}^{*}\right)-\sqrt{\left[1+\delta\left(1-A_{j}^{*}\right)\right]^{2}+2 \delta^{2} d^{2}}\right] / 2 \delta, d-A_{j}^{*}\right\}$, where $\Delta_{-}$decreases in $A_{j}^{*}$. Hence, if $A_{j}^{*} \geq d, A^{1}=A_{j}^{*}+\tilde{\Delta}_{-}$, so that $A^{1} \in\left(d, A_{j}^{*}\right)$.

Proof of Proposition 7. If $d<1 / 2$, a Pro- $V$ judge sets $A^{1}$ in $\{0,1 / 2-d, 1-d\}$. $A_{V}^{*}=0$; with $1 / 2-d$ and $1-d$ the Unbiased and Pro-O judges do not overrule, respectively. A Pro-O judge sets $A^{1}$ in $\{1,1 / 2+d, d\} . A_{O}^{*}=1$; with $1 / 2+d$ and $d$ the Unbiased and Pro- $V$ judges do not overrule, respectively. An Unbiased judge sets $A^{1}$ in $\{1 / 2, d, 1-d\} . A_{U}^{*}=1 / 2$; with $1-d$ and $d$ the Pro-O and Pro-V judges do not overrule, respectively. There are two cases to consider.

a. $d<1 / 4$. A Pro- $V$ judge gets $(\delta / 4)[2-\gamma]$ if $A^{1}=0 ;(1 / 2-d)^{2}+\delta\left[(1 / 2)(1-\gamma)+\gamma(1 / 2-d)^{2}\right]$ if $A^{1}=1 / 2-d,(1-d)^{2}+\delta\left[(1 / 2)(1-\gamma)(1-d)^{2}+\gamma(1 / 4)\right]$ if $A^{1}=1-d$. The judge prefers 0 to $1-d$. 
He thus sets $1 / 2-d$ iff $\gamma \geq \gamma_{B, 1}=(1 / 2-d)^{2} / \delta d(1-d)$. Judges' behavior is symmetric, hence in the same case a Pro-O sets $A^{1}=1 / 2-d$. What does an Unbiased judge do?. He gets $\delta(1-\gamma)(1 / 4)$ if $A^{1}=1 / 2, \quad(1 / 2-d)^{2}+(\delta(1-\gamma) / 2)\left[(1 / 2-d)^{2}+1 / 4\right]$ if $A^{1}=d$ or if $A^{1}=1-d$. He thus sets $1 / 2$ iff $\gamma \geq \gamma_{U, 1}=1-(1 / 2-d)^{2} /(\delta / 2) d(1-d)$. Thus, for $\gamma \geq \gamma_{1}=\max \left(\gamma_{U, 1}, \gamma_{B, 1}\right)$, Pro- $V$, Unbiased and Pro-O judges set $A^{1}=1 / 2-d, 1 / 2+d$ and $1 / 2$ respectively.

b. $d \geq 1 / 4$. A Pro-V judge gets $(1 / 2-d)^{2}+\delta\left[(1 / 2)(1-\gamma)+(1 / 2)(1+\gamma)(1 / 2-d)^{2}\right]$ if $A^{1}=1 / 2-d$, $(1-d)^{2}+\delta(1 / 2)(1+\gamma)(1-d)^{2}$ if $A^{1}=1-d$. The judge prefers chooses $1 / 2-d$ over $1-d$ whenever $\gamma \geq \gamma_{O V}=[d+(\delta / 2)(1 / 4+d)-3 / 4] /(\delta / 2)(14 / 8-d) \quad$ and $\quad 1 / 2-d \quad$ over $\quad 0 \quad$ iff $\gamma \geq \gamma_{V U}=(1 / 2-d)^{2}(1+\delta / 2) /\left(1 / 4-d^{2}\right)$. He thus sets $A^{1}=1 / 2-d$ iff $\gamma \geq \gamma_{B, 2}=\max \left(\gamma_{O V}, \gamma_{V U}\right)$.

In the same case a Pro-O judge sets $A^{1}=1 / 2+d$. An Unbiased judge gets $\delta(1-\gamma)(1 / 4)$ if $A^{1}=1 / 2$, $(1 / 2-d)^{2}+\delta\left[(1 / 2)(1+\gamma)(1 / 2-d)^{2}+(1-\gamma) / 8\right]$ if $A^{1}=d \quad$ or if $A^{1}=1-d$. He sets $A^{1}=1 / 2$ iff $\gamma \geq \gamma_{U, 2}=\left[(\delta / 2) d(1-d)-(1 / 2-d)^{2}\right] /\left(d^{2}-d+1 / 2\right) . \quad$ For $\quad \gamma \geq \gamma_{2}=\max \left(\gamma_{U, 2}, \gamma_{B, 2}\right), \quad$ Pro-V , Unbiased and Pro-O judges set $A^{1}=1 / 2-d, 1 / 2+d$ and $1 / 2$ respectively. To conclude the proof, set $\tilde{\gamma}$ equal to $\gamma_{1}$ if $d<1 / 4$ and equal to $\gamma_{2}$ if $d \in[1 / 4,1 / 2)$. 


\section{Bibliography}

Brenner, Saul, Spaeth, Harold, J., 1995. Stare Indecisis: The Alteration of Precedent on the U.S. Supreme Court, 1946-1992. Cambridge University Press, New York, NY.

Brenner, Saul, Stier, Marc, 1996. Retesting Segal and Spaeth’s Stare Decisis Model. American Journal of Political Science 40, 1036-1048.

Cooter, Robert, D., Kornhauser, Lewis, A., 1979. Can Litigation Improve the Law without the Help of Judges. Journal of Legal Studies 9, 139-163.

Cooter, Robert, D., Kornhauser, Lewis, A., Lane, David, 1979. Liability Rules, Limited Information, and the Role of Precedent. Bell Journal of Economics 10, 366-373.

Frank, Jerome, N., 1930. Law and the Modern Mind. Brentano’s, New York, NY.

Gennaioli, Nicola, 2004. Contracting in the Shadow of the Law. Mimeo. Harvard University.

Gennaioli, Nicola, Shleifer, Andrei, 2007. The Evolution of Common Law. Journal of Political Economy, forthcoming.

George, Tracey, E., Epstein, Lee, 1992. On the Nature of Supreme Court Decision Making. American Political Science Review 86, 323-337.

Hansford, Thomas, G., Spriggs II, James, F., 2006. The Politics of Precedent in the U.S. Supreme Court. Princeton University Press, Princeton, N.J.

Holmes, Oliver Wendell, 1897. The Path of the Law. Harvard Law Review 10, 457-478.

Klein, David, E., 2002. Making Law in the United States Courts of Appeals. Cambridge University Press, Cambridge, U.K.

Kornhauser, Lewis, A., 1992. Modeling Collegial Courts, II. Legal Doctrine. Journal of Law, Economics, and Organization 8, 441-470.

Landes, William, M., Posner, Richard, A., 1987. The Economic Structure of Tort Law. Harvard University Press, Cambridge, MA. 
La Porta, Rafael, Lopez-de-Silanes, Florencio, Pop-Eleches, Cristian, Shleifer, Andrei, 2004.

Judicial Checks and Balances. Journal of Political Economy 112, 445-470.

MacKuen, Michael, B., McGuire, Kevin, T., 2005. Precedent and Preferences on the U.S. Supreme Court. Mimeo. University of North Carolina, Chapel Hill.

Pinello, Daniel, R., 1999. Linking Party to Judicial Ideology in American Courts: A Meta-analysis. The Justice System Journal 3, 219-254.

Posner, Richard, A., 2003 ( $1^{\text {st }}$ ed. 1973). The Economic Analysis of Law, $6^{\text {th }}$ ed. Little Brown, Boston, MA.

Posner, Richard, A., 2005. Judicial Behavior and Performance: an Economic Approach. Florida State University Law Review 32, 1259-1279.

Priest, George, L., 1977. The Common Law Process and the Selection of Efficient Rules. Journal of Legal Studies 6, 65-82.

Radin, Max, 1925. The Theory of Judicial Decision: or How Judges Think. American Bar Association Journal xx, 357-362.

Revesz, Richard, L., 1997. Environmental Regulation, Ideology, and the D.C. Circuit. Virginia Law Review 83, 1717-1772.

Rowland, Charles, K., Carp, Robert, A., 1996. Politics and Judgment in Federal District Courts. The University Press of Kansas, Lawrence, KS.

Rubin, Paul, H., 1977. Why is the Common Law Efficient?. Journal of Legal Studies 6, 51-63.

Schwartz, Edward, P., 1992. Policy, Precedent, and Power: A Positive Theory of Supreme-Court Decision Making. Journal of Law, Economics, and Organization 8, 219-252.

Segal, Jeffrey, A., Spaeth, Harold, J., 1996. The Influence of Stare Decisis on the Votes of the United States Supreme Court Justices. American Journal of Political Science 40, 971-1003.

Segal, Jeffrey, A., Spaeth, Harold, J., 2002. The Supreme Court and the Attitudinal Model Revisited. 
Cambridge University Press, New York, NY.

Songer, Donald, R., Lindquist, Stefanie, A., 1996. Not the Whole Story: The Impact of Justices’ Values on Supreme Court Decision Making. American Journal of Political Science 40, 1049-1063.

Spiller, Pablo, T., Tiller, Emerson, H., 1997. Decision Costs and the Strategic Design of Administrative Process and Judicial Review. Journal of Legal Studies 26, 347-370.

Stone, Julius, 1985. Precedent and the Law: Dynamics of Common Law Growth. Butterworths, Sydney, Australia.

Sunstein, Cass, R., Schkade, David, A., Ellman, Lisa Michelle, 2004. Ideological Voting on Federal Courts of Appeals: a Preliminary Investigation. Stanford Law Review 90, 301-354. 